УДК 81 '42

DOI: $10.33184 / Y V D K-2021-04-30.5$

Е.С. Лукашева (студент ОГУ, г. Оренбург),

И.А. Солодилова (проф. ОГУ, г. Оренбург)

\title{
ЛИНГВОДИСКУРСИВНОЕ СВОЕОБРАЗИЕ ЖУРНАЛОВ СФЕРЫ АВТОСПОРТА
}

В данной статье представлень результаты сопоставительного анализа немецких и российских журналов сферы автоспорта. Исследование было проведено с целью выявления значимых для автоспортивного дискурса стратегий, определяюших его своеобразие.

Ключевые слова: дискурс, автоспортивный, стратегии, лингво-дискурсивный.

The article presents the results of a comparative analysis of German and Russian motorsport magazines. The study was carried out in order to identify strategies that are significant for the motorsport discourse that determine its originality.

Key words: discourse, motorsport, strategies, linguisticdiscursive.

Автоспортивный дискурс является гетерогенным образованием, объединяющим в себе черты различных типов дискурса и различных функциональных стилей. Журнальная пресса как одна из наиболее распространенных форм реализации автоспортивного дискурса обуславливает его тесную связь с дискурсом СМИ, содержательная и тематическая направленность - наличие характеристик научно-технического стиля, а прагматическая заданность - привлечение внимания целевой аудитории к автоспортивным мероприятиям и автомобилям сближает его с дискурсом рекламы. Это формально-структурное, содержательно-тематическое и прагматическое своеобразие предопределило свойственную именно автоспортивному дискурсу совокупность стратегий, реализующихся в текстах автоспортивных журналов определенным набором языковых средств. 
Основополагающими стратегиями автоспортивного дискурса, как выявило исследование, являются высокая информативность, доступность и налляность представления информации, экспрессивность изложения, «патриотичность», рекламность, прямолинейность в выражении оценки и полемичность. Последние две выступают как противоположные тенденции, дополняющие друг друга до целого.

Стратегия информативности реализуется в российских и немецкоязычных автоспортивных журналах через высокую содержательную точность и иллюстративность представляемой информации, а также через высокую долю технической терминологии и профессионализмов в лексическом оформлении текстов.

В этом отношении язык автоспортивных журналов проявляет характеристики научно-технического стиля, одной из главных стилевых черт которого и является информативность и точность изложения. Эта особенность обусловлена одной из задач автоспортивной прессы - информационное обслуживание целевой аудитории. Решение этой задачи и, соответственно, реализация названной стилевой черты достигается за счет использования цифровых $u$ статистических данных, профессиональной терминологии и иллюстративности, свойственной вообще журнальной прессе, но имеющую в автоспортивных журналах иное целевое предназначение. В отличие, например, от развлекательных журналов, иллюстрации в журналах автоспорта используются не для привлечения внимания, а в качестве средства предоставления дополнительной - более детальной информации. Основными видами иллюстративного материала такого типа являются таблицы, фотографии, схемы, чертежи, диаграммы и т.п.

Информативность как дискурсивная стратегия свойственна в одинаковой мере как немецким, так и российским автоспортивным журналам. Отличия в использовании средств уточнения и детального изложения касаются объектов описания. Так, если немецкоязычные журналы большей частью информируют читателя о достижениях пилотов и команд, то российские преимущественно включают в себя характеристики гоночных автомобилей.

Понятийная точность описания достигается за счет 
использования технической терминологии, что также является стилевым признаком текстов научно-технического стиля. В качестве примера приведем отрывок из статьи Василия Костина «Окна GTE» журнала «Авторевю» за 2020 год: «Здесь хорошо видно замысловатую форму переднего сплитмера Ferrari c дефлекторами по краям. Центральные воздухозаборники нужны для обдува радиаторов, а боковые - для охлаждения тормозов (нижний патрубок) и кокпита (верхний)» (1) (Выд. - нами, Е.Л., И.С.).

Среди немецких терминов и профессионализмов частотными также являются названия деталей автомобилей: Nase und Frontflügel, Motor, Heck, Getriebe, а также принятые в немецкоязычном автоспортивном дискурсе сокращения: $M G U-K$ (kinetische Energie), MGU-H(Heat), 1,6-Liter-V6-Motor, Turbolader и др.

Совокупность выявленных в результате анализа текстов автоспортивных журналов стратегий доказывает выдвинутую нами гипотезу о стилевой гетерогенности автоспортивного дискурса, проявляющуюся в наличии у него дискурсивных и стилевых черт разных типов дискурсов и функциональных стилей. Если высокая точность изложения материала и информативность - это то, что автоспортивные журналы заимствовали у научно-технического стиля, то образность, широко используемая в обоих исследуемых нами дискурсов, отсылает к публицистическому и художественному стилям.

Использование образных средств и тесно связанного с ним (в данном типе дискурса) принциипа интертекстуальности служит реализации еще одной значимой для автоспортивного дискурса стратегии - стратегии наглядности и яркости представления информации. Эти стратегии позволяют, по нашему мнению, добиться в текстах автоспортивных журналов емкости и лаконичности изложения. Следует при этом сказать, что в отличие от художественного стиля используемые здесь средства образности - метафоры, аллюзии, идиоматические выражения являются понятными большинству читателей, поскольку основаны на общей для данного национально-культурного сообщества фоновой информации. Оставаясь все же экспрессивными средствами, они успешно реализуют прагматическую функцию привлечения внимания. 
Особого внимания, на наш взгляд, заслуживают аллюзии, широко используемые в немецкоязычных автоспортивных журналах. Их использование в автоспортивном дискурсе служит реализации двух целей: во-первых, лаконичности передачи авторского замысла через содержательно емкий (в силу известности) литературный / кинематографический образ, и, вовторых, в силу их представленности прежде всего в заголовках статей - привлечению внимания читателя.

В качестве примера хотелось бы привести статью Михаэля Хёллера в журнале «Motorsport-magazin.com» (№ 55) с заголовком «Der Zauberlehrling», который отсылает (конечно, осведомленного) читателя к одноименной балладе Иоганна Вольфганга фон Гёте («Und nun komm, du alter Besen, Nimm die schlechten Lumpenhüllen! Bist schon lange Knecht gewesen: Nun erfülle meinen Willen!». Приведем еще один пример. Заголовок «Mein Name ist Sutil - Adrian Sutil» (3) является аллюзией фразы «Mein Name ist Bond - James Bond" из серии фильмов о вымышленном агенте MI6 Джеймсе Бонде.

Отсылки к отечественной литературе встречаются (хотя значительно реже) и в статьях российских журналистов. Рассуждению о нескольких поколениях гонщиков Формулы-1 журналист Сергей Иванов даёт заголовок «Отцы и дети», отсылая читателя к одноименному роману И.С. Тургенева.

Привлечению внимания служат и фразеологические единицы, особенно модифицированные. «Ein kleines Licht am Ende des Feldes» (3) отсылает к ставшему крылатым выражению «ein Licht am Ende des Tunnels sehen» Модифицированный характер фразеологических единиц обеспечивает эффект обманутого ожидания, вызывая, как правило, улыбку, заставляя читателя (в данном случае через заголовок) обратиться к самой статье.

Не менее широким является использование пословиц и поговорок: «Стены не помогли. Себастьен Ожье мог досрочно стать двукратным чемпионом мира на ралли в его родной Франции. Но родные стены не помогли: в кои-то веки отказал непобедимый Volkswagen Polo R WRC!» (1)].

Широкое использование идиом, в том числе модифицированных и аллюзий обусловлено их способностью, сохраняя яркость и небанальность изложения, оставаться 
понятными и быстро декодируемыми, что, свойственно газетнопублицистическому стилю, основополагающей чертой которого является сочетание стандартизованного характер изложения и яркости представления. Именно поэтому и метафоры, используемые в текстах автоспортивных журналов, являются большей частью узуальными.

Экспрессивность и яркость изложения материала достигаются также за счет использования языковой игры, которая, на наш взгляд, является наиболее популярным, но и наиболее сложным в лингвистическом отношении средством, использующимся журналистами сферы автоспорта. Данный приём активно применяется, как немецкими авторами, так и их российскими коллегами именно в текстах заголовков. Наиболее частотными являются каламбуры на лексической основе, которые, однако, нуждаются в дальнейшем пояснении (из-за узкого контекста заголовка) для успешного декодирования и понимания. В рамках автоспортивного дискурса прием игры слов выполняет с одной стороны, функцию привлечения внимания за счет эффекта комичности и обманутого ожидания, а с другой является емким семантическим средством передачи авторского замысла.

В качестве примера использования языковой игры в немецкоязычных журналах приведем заголовок «Scheinheiliger Heiligenschein?», имеющий подзаголовок, который поясняет, что речь идёт о системе дополнительной защиты головы Halo (в переводе с английского на немецкий означает «Heiligenschein»). Игра слов отсылает к сомнению об эффективности этой защиты: «2018 wird der Cockpit-Schutz Halo in der Formel 1 eingeführt. Doch es gibt am unästhetischen Bügel mehr Kritik als nur die Optik. Warum die nicht immer berechtigt ist und wie sich die FIA selbst in die Zwickmühle brachte» (2).

В российских журналах языковая игра представлена очень широко: «Тех ли требования?» (с отсылкой к ЛЕ технические требования), «Квали ... Фикция» (обыгрывается неудачный результат нововведений в рамках системы квалификации Формулы-1), «Нашкодили» (языковая игра основана на контаминации глагола нашкодить и названия марки автомобиля Шкода: «Правда, в финале европейского сезона, на легендарном французском ралли Тур де Корс, где доминировали хозяева трассы Стефан Сарразен и Бриан Буффье на хэтчбеках Ford Fiesta RRC, 
оба гонщика чешском команды «нашкодили». Машина Виганда сгорела после аварии на предстартовых тестах, а Лаппи разбил свою Фабию в середине ралли...» (1).

Игра слов, как лингводискурсивная характеристика автоспортивных журналов, широко представлена как в немецких, так и в российских изданиях. Привлекая внимание читателя, заголовки, построенные на игре слов, отсылают часто к экстралингвистической реальности - фильмам, книгам, событиям из жизни спортсменов, их ценностям и т.п., т. е. к дискурсивным параметрам текста. Сложность интерпретации исходя из исключительно контекста самого заголовка снимается дополнительным пояснением, содержащемся внутри подзаголовка или основного текста. Лидирующее место занимают здесь каламбуры на лексической основе.

Исследование позволило выявить еще одну стратегию автоспротивного дискурса - стратегию патриотизма, которая свойственна спортивному дискурсу вообее Концепт ПАТРИОТИЗМ относится к тем ментальным единицам, которые входят в «общий алфавит культуры» [Садомирская, 2001], являются «универсалиями духовной культуры», «лингвоконцептами высшего уровня, «лингвокультурной идеей», имеющей сложное семантическое образованием гиперонимического типа, поскольку включает в себя концепты и „,антиконцепты“: РОДИНУ и ЧУЖБИНУ, СВОЕ и ЧУЖОЕ [Воркачев 2003: 45].

Анализ содержания текстов автоспортивных журналов позволил установить, что в рамках автоспортивного дискурса, как части более глобального - спортивного дискурса, концепт ПАТРИОТИЗМ активно реализуется и прежде всего с помощью лексических единиц с положительной оценочной семантикой (в примерах выделено курсивом). Журналисты российских и немецких изданий не скупятся на похвалу автоспортивных заслуг своих гонщиков, команд и чемпионатов:

«Wenn der liebe Gott einen Cocktail gemixt hätte mit den besten Eigenschaften eines Rennfahrers, wäre Sebastian Vettel dabei herausgekommen», sagt Mercedes-Aufsichtsratschef Niki Lauda, selbst dreimal Weltmeister (1975, 1977, 1984). Vettel had das Beste aller herausragenden Eigenschaften von Fangio, Prost und Schumacher in sich» (3) 
«А Даниил в Сочи ярко показал свои возможности в квалификации, заняв пятое место, - впереди обоих гонщиков Red Bull! Правда, в самой гонке переволновался и выступил хуже, не заработав очков. Что ж, это не так уж и важно - главное у Даниила впереди». Однако, не только труд пилота оценивает журналист положительно, но и само событие, прошедшее на территории России: «Кубанский казачий хор грянул российский гимн - и первый Гран При на нашей земле был официально открыт. Высокий уровень организации, энтузиазм зрителей, красивый антураж Гран При России - это увидели все. А вот обгонов было маловато...» (1).

Со стратегией патриотичности тесно связана и стратегия рекламности, которая также реализуется с помощью выражения положительной оценки (по отношению к своим).

Прямое выражение авторской оценки является лингводискурсивной характеристикой, свойственной исключительно автоспортивному дискурсу. Если для медиадискурса, особенно в сфере внутренней и внешней политики, более приемлемым является непрямое, косвенное выражение оценочного отношения, часто иносказательное или «скрытое между строк», то автоспорт в СМИ наслаждается открытостью в выражении своих симпатий и антипатий. Объяснение этому обстоятельству достаточно просто: автоспортивная тематика не относится к щепетильным темам политики и социальной жизни, где необходимо соблюдать политкорректность, дабы не обидеть оппонента и не попасть в неловкую ситуацию, когда нужно «держать ответ» за свои слова. Напротив, тяготея по своей семиантико-прагматической направленности в определенной степени к рекламному дискурсу, автоспортивные журналы демонстрируют ярко выраженную тенденцию к прямому выражению оценки, Особенностью выражения отрицательного оценочного отношения является непринужденный стиль речи, достигаемый употреблением разговорной, разговорно-фамильярной лексики, что позволяет автору снизить жесткость и нелицеприятный характер слов, достигая тем самым в определенном смысле эффект эвфимизации.

Так, Михаэль Хёллер, журналист «MotorsportMagazin.com» пишет: «Haters gonna hate. Dieser bekannte Spruch hat sich am 26. Februar wieder einmal bewahrheitet. Als an jenem 
Montag Honda die Vertragsverlängerung mit Marc Marquez bekanntgab, ließen sich unzählige MotoGP-Fans aus der AntiMarquez-Fraktion in den sozialen Medien dazu hinreißen, diese Entscheidung als feige zu diffamieren». Отрицательная оценка выражена в данном примере эксплицитно - с помощью отрицательного предиката этической оценки - feige и оценочного по своей семантике глагола diffamieren (порочить, оклеветать). Резкость отрицательной оценки снижается шуточным характером текста, достигаемым за счет использования английского выражения «Haters gonna hate». Возникшее и распространившееся в американском хип-хопе, впервые оно было использовано в тексте песни группы 3LW 2000 года „Playas gon' play”. Данная фраза является частью выражения «Playas they gonna play and haters they gonna hate», что в свою очередь буквально переводится как «Игроки будут играть, а ненавистники будут ненавидеть». Как видим, и здесь не обошлось без приема интертекстуальности, что имеет целью (кроме лаконичности изложения) выделение «своих», «посвященных» (тот, кто понял, свой).

Эксплицитный характер оценки свойственен и российским автоспортивным журналам: «Рома говорит глухим низким баритоном, словно только что съел слишком много мороженого. Его приятно слушать, в рассказе нет типичных выученных и вышколенных фраз. А ещё мне нравится, что в рейдах гонщики похожи на спортсменов, а не на переусердствовавших в учёбе студентов, как нынешнее поколение пилотов Формулы-1.» В данной статье журналист открыто выражает свои впечатления и эмоции относительно личных и профессиональных качеств гонщика Хуана Нани Рома

Противоположной вышеописанной характеристике прямого выражения оценки является полемичное изложение точки зрения с приведением логических доказательств. Тем самым журнальных издания автоспорта достигают определенного рода баланс между представлением точки зрения определенного коллектива авторов и предоставлением возможности читателям самостоятельно сформировать свой взгляд на ту или иную проблему.

Для журнала «Motorsport-magazin.com» характерно, что для статей типа «Pro \& Contra» аргументацию в пользу того или иного явления выполняют два разных автора. Например, в статье 
«Pro \& Contra. Hersteller-Boom in der Formel E: Fluch oder Segen?» Флориан Бекер выступает «за», а его коллега Роберт Зейверт «против» При этом, они активно задают друг другу вопросы, что несомненно побуждает читателя к собственным размышлениям: «Fernando Alonso gegen Felipe Massa in der Formel E? Warum nicht...», «Da hilft dann auch kein Fan-Boost mehr. Passt das ins ursprüngliche Konzept?», «Das hat in der Vergangenheit nicht selten das Ende einer Rennserie eingeleitet. Gehen dann auch in der Formel E die Lichter aus?» (2).

Необходимо, однако, отметить, что данная характеристика свойственна, в большей мере, немецкому автоспортивному дискурсу. Это связано, на наш взгляд, как с более длительным присутствием немецких гонщиков и команд в ведущих гоночных сериях, так и с нарастающей потребностью проведения анализа их выступлений в СМИ.

Подводя итог, хотелось бы подчеркнуть, что языковое оформление текстов автоспортивных журналов определяется реализацией лингво-дискурсивных стратегий. Наряду со строгостью синтаксического оформления, свойственной письменной речи, стилистической нейтральностью профессиональной лексики и технической терминологии язык автоспортивных журналов характеризуется и наличием разговорной, разговорнофамильярной, экспрессивной лексики и синтаксиса, что является неотьемлемой характеристикой эмоционально-ценочной речи.

ЛИТЕРАТУРА

1. Воркачев, С.Г.Культурный концепт и значение. [Электронная_версия печ. пуболкации] /Воркачев С. Г // Труды Кубанского государственного технологического университета. Сер. Гуманитарные науки. Т. 17, вып. 2. Краснодар, $2003 \quad-\quad$ c. $268-276 \quad$ // http://kubstu.ru/docs/lingvoconcept/meaning.htm

2. Сандомирская И. Книга о Родине: Опыт анализа дискурсивных практик. Wien, 2001.-282 c.

\section{СПИСОК ИСТОЧНИКОВ}

1. Авторевю: газета / Учредитель Михаил Подорожанский. - 1995, февраль Издательство ООО «Авторевю». 2019, №19 (550), №20 (551), №21 (552); 2020, №1 (556), №6 (584), №8 (586),, №10 (588)

2. Motorsport-magazin.com. adrivo $\mathrm{GmbH} 2019, \mathrm{nr} .55, \mathrm{nr} .56 ; 2020, \mathrm{nr} .59$.

3. Sport Bild Sonderheft Formel 12019. Axel-Springer SE.

С Лукашева Е.С., СолодиловаИ.А.,2021 г. 